\title{
Regulation of Anti-Inflammatory Activity of Intravenous Immunoglobulin via Inhibitory Fe $\gamma$ Receptors
}

\author{
A review of: Samuelsson A, Towers TL, Ravech JV 2001 Anti-inflammatory activity of IVIG mediated through the
} inhibitory Fc receptor. Science 291:484-486

$\mathrm{I}$ NTRAVENOUS IMMUNOGLOBULIN (IVIG) preparations are able to modulate the course of inflammatory/autoimmune diseases, in addition to their anti-toxic and anti-microbial action. The therapeutic efficacy of IVIG is most encouraging in diseases mediated by pathogenic auto-antibodies against cells and tissues, such as in immune thrombocytopenic purpura (ITP) (1). In ITP, macrophages recognize and phagocytose platelets coated with anti-platelet antibodies through the low-affinity, activating Fc receptor, Fc $\gamma$ RIII.

Based on studies in a murine model of ITP, Samuelsson et al. proposed that the major player mediating antiinflammatory action of IVIG is the Fc $\gamma$ RIIB, an inhibitory Fc $\gamma$ receptor for IgG (2). The authors showed that clinically relevant doses of intact IVIG prevented platelet consumption in experimental ITP induced by intravenous injection of anti-platelet autoantibody in wild-type mice. Only the monomeric Fc fragments, but not the Fab portion of IgG conferred the protective effect of IVIG, suggesting the involvement of Fc $\gamma$ receptors. Protection was associated with the ability of IVIG administration to induce surface expression of Fc $\gamma$ RIIB on splenic macrophages. Intriguingly, IVIG induced a $60 \%$ increase in the number of macrophages expressing Fc $\gamma$ RIIB, but it did not increase the maximal expression of Fc $\gamma$ RIIB by these cells. Paralysis of Fc $\gamma$ RIIB function by genetic engineering or with blocking monoclonal antibodies $(\mathrm{mAb})$ reversed the therapeutic effect of IVIG. The authors also reported that genetic deletion of Fc $\gamma$ RIII

\section{LÁSZLÓ MARÓDI}

resulted in protection from ITP, whereas deleting the high-affinity activating Fc $\gamma \mathrm{R}$, Fc $\gamma \mathrm{RI}$, was not protective (2). They concluded that the major effect of IVIG in protection against ITP is its ability to induce expression of the inhibitory Fc $\gamma$ RIIB receptor on macrophages.

Samuelsson et al. do not provide information on the molecular mechanism of IVIG-induced expression of Fc $\gamma$ RIIB or on how surface expression of FcRIIB inhibits platelet uptake by macrophages. It is likely that activation responses triggered by immune complexes may be counterbalanced by inhibitory mechanisms, such as upregulation of the inhibitory Fc $\gamma$ RIIB. In immune complex-triggered inflammation, the inhibitory FcRIIB was actually shown to counteract Fc $\gamma$ RIIImediated activation responses (3). Such a regulatory coupling might occur in macrophages exposed to IVIG containing complexed IgG. In addition to monomeric IgG, IVIG preparations contain substantial amounts of $\mathrm{IgG}$ dimers (4). IVIG prepared from thousands of blood donations contains antiidiotypes recognizing other antibodies present in the preparation. These antiidiotypes may pair with the complementary idiotype to form a dimeric structure. Studies from our laboratory have shown that IVIG exposure triggers superoxide anion release and elicits a vigorous increase in the concentration of cytosolic free calcium in human granulocytes (5). Granulocyte activation evoked by IVIG was signif- icantly decreased if activities of Fc $\gamma$ RIIA and Fc $\gamma$ RIII receptors were blocked by mAbs.

The clinical relevance of the study by Samuelsson et al. may be somewhat questioned by the fact that IVIG was administered before inducing the disease in mice in contrast to giving IVIG infusions in human patients with fullblown ITP. Nevertheless, their data suggest that modulation of inhibitory signaling may be a therapeutic strategy for attenuating antibody-triggered inflammatory diseases. Individual differences in the regulation of Fc $\gamma$ RIIB expression might provide a basis for predicting which ITP patient will respond most rapidly and strongly to IVIG therapy.

1. Imbach P, Barandun S, d'Apuzzo V 1981 High dose intravenous gammaglobulin for idiopathic thrombocytopenic purpura in childhood. Lancet i:1228-1231

2. Samuelsson A, Towers TL, Ravetch JV 2001 Antiinflammatory activity of IVIG mediated through the inhibitory Fc receptor. Science 291:484-486

3. Clynes R, Maizes JS, Guinamard R, Ono M, Takai T, Ravetch JV 1999 Modulation of immune complex-induced inflammation in vivo by the coordinate expression of activation and inhibitory Fc receptors. J Exp Med 189:179-185

4. Tankersly DL 1994 Dimer formation in immunoglobulin preparations and speculations on the mechanism of action of intravenous immunoglobulin in autoimmune diseases. Immunol Rev 139:159-172

5. Nemes É, Teichman F, Roos D, Maródi L 2000 Activation of human granulocytes by intravenous immunoglobulin preparations is mediated by Fc $\gamma$ RIIA and Fc $\gamma$ RIII receptors. Pediatr Res 47:357-361

University School of Medicine Infectology and Pediatric Immunology Nagyerdei Krt 98

Debrecen

HU-4012

Hungary 